\title{
Association between Children's Saving Account and Parent Rated Children's Health: A Preliminary Study
}

\author{
Anao Zhang ${ }^{1}$, Zibei Chen ${ }^{1}$, Kaipeng Wang ${ }^{2}$, William Elliott ${ }^{1}$, So'phelia Morrow $^{1}$ \\ ${ }^{1}$ School of Social Work, University of Michigan, Ann Arbor, MI, USA \\ ${ }^{2}$ School of Social Work, Texas State University, San Marcos, TX, USA \\ Email: *willelli@umich.edu
}

How to cite this paper: Zhang, A. A., Chen, Z. B., Wang, K. P., Elliott, W., \& Morrow, S. (2020). Association between Children's Saving Account and Parent Rated Children's Health: A Preliminary Study. Sociology Mind, 10, 1-14.

https://doi.org/10.4236/sm.2020.101001

Received: September 3, 2019

Accepted: November 23, 2019

Published: November 26, 2019

Copyright ( 2020 by author(s) and Scientific Research Publishing Inc. This work is licensed under the Creative Commons Attribution International License (CC BY 4.0).

http://creativecommons.org/licenses/by/4.0/

\section{(c) (i) Open Access}

\begin{abstract}
Children's Savings Accounts (CSAs) are interventions designed to build educational assets for school-age children. The positive effects of having a CSA has been established for mental health and developmental outcomes, yet no studies to date have examined how CSAs affect children's physical health. This study uses data from Harold Alfond College Challenge, the oldest and one of the most well-known CSA programs in the United States, to evaluate the association between a CSA and children's physical health status measured by parent-rated children's health. Results indicate CSA ownership is associated with a greater chance of reporting excellent or very good health than those families who did not receive a CSA. Implications on research and CSA programs are discussed.
\end{abstract}

\section{Keywords}

Children's Savings Account, Financial Security, Parent-Rated Children's Health

\section{Background and Significance}

Financial security refers to a peace of mind that one does not feel worried about his/her financial situation to cover life expenses (Carstensen, 2011). It is a well-established social determinant of an individuals' physical and mental health well-being (Adler, Glymour, \& Fielding, 2016; de Andrade et al., 2015). Previous theories suggest that financial security is reflective of one's overall socio-economic status and an indicator of an individual's psychological stress, health behaviors, and physical health well-being (e.g., Carstensen, 2011; Diez Roux, 2012). Child- 
ren's Savings Accounts (CSAs) are programs designed to address financial insecurity through saving mechanisms to encourage saving and building assets for disadvantaged youth and families who do not have equitable access to financial institutions (Sherraden, 1991). While the design and implementation of CSA programs vary, they usually allow deposits from children, their parents and other relatives, and third parties such as scholarship programs. Ideally these investments are leveraged with an initial deposit and/or matching funds adding public or philanthropic funds to families' savings, usually on a ratio ranging from 1:1 to 5:1.

A component of CSAs is to encourage low-income savers to engage in saving activities by providing meaningful incentives that often are only available to higher-income households (such as tax benefits). However, a CSA is more than its financial component. In his groundbreaking book, Assets and the Poor. A New American Welfare Policy, Michael Sherraden (1991) postulated that owning assets can produce multiple economic and psychological effects. Specifically, he posits that assets improve household stability, increase personal efficacy and political participation, create an orientation toward the future, enable focus or specialization, and provide a foundation for risk taking. The potential for multiple effects has made assets a particularly alluring and fast-growing policy strategy for improving the well-being of low-income families. By 2018, there were 54 CSA programs serving 382,000 children in more than 32 states (Prosperity Now, 2018). The Harold Alfond College Challenge (HACC), examined in this study, is the oldest and one of the most recognizable CSA programs in the United States.

\section{Program Description}

Maine's Harold Alfond College Challenge (HACC) program is an investment in the educational and economic futures of Maine's children, aiming not only to help Mainers make it to college, but also to position them for success once in college and to leverage educational success for financial prosperity for individuals and the entire state. In 2008, HACC started as a pilot program in two hospitals in the state of Maine, and in 2009 it was offered to all Mainers. HACC is the first statewide CSA program in the United States making it an important program to study. Each year since 2009, HACC has offered a $\$ 500$ grant to residents of Maine who have a newborn. To be eligible for a HACC grant in the first five years of the program, Alfond Grants were awarded when a NextGen 529 account was opened by the child's first birthday. NexGen is the name for Maine's 529 plan. Savings received from accountholders are currently matched at a rate of 50 cents on the dollar with a maximum annual match of $\$ 300$ available to participants. An additional $\$ 100$ match is offered when parents set up automatic deposit (for more information on the HACC program see Lewis \& Elliott (2015) ${ }^{1}$. Importantly, in 2014 HACC shifted from an opt-in program where families had ${ }^{1}$ FAME's grant programs support all Maine NextGen accounts including those with an Alfond Grant. 
to sign up to receive the $\$ 500$ HACC grant, to an opt-out program where all families are automatically enrolled at birth, about 12,000 births children per year (Powell, 2014). This change to automatic enrollment was made to include all Maine resident babies born on or after January 1, 2013. The shift from opt-in to opt-out reflects a growing consensus in the field of CSAs that the only way to include everyone is through automatic enrollment.

\section{Review of Research on CSA}

The potential indirect effects of the program have led to the expansion of these small-dollar CSAs (Elliott \& Lewis, 2018; Sherraden, 1991). For example, a randomized experiment conducted by the Center for Social Development, SEED for Oklahoma Kids (SEED OK), has shown a causal relationship between CSAs and higher parental educational expectations, especially among low-income families (Kim, Sherraden, Huang, \& Clancy, 2015). Correlational studies using national data sets have found that children who have savings set aside for college have higher math scores (Elliott, Kite, O’Brien, Lewis, \& Palmer, 2018), higher educational expectations (Elliott, 2009), and are more likely to attend and complete college (Elliott, 2013). A recent randomized experiment in Italy further evidenced the causal relationship between CSAs and college enrollment as well as performance while in college (Azzonlini et al., 2018).

In addition to academic outcomes, research also investigated the relationship between CSAs and mental health outcomes of children and their parents. For instance, SEED OK examined the effects of CSAs on children's social and emotional skills and found that infants who were randomly assigned to receive the SEED OK account at birth demonstrated significantly higher social-emotional skills at age four than their counterparts who did not receive the CSA (Huang, Sherraden, Kim, \& Clancy, 2014). SEED OK research has further explored the dynamics believed to explain these effects, citing reductions in mothers' depressive symptoms (Huang, Sherraden, \& Purnell, 2014) and its mitigative effects on the relationship between material hardship and children's social and emotional well-being (Huang, Kim, \& Sherraden, 2016). This may be one way that CSAs improve the conditions that influence children's outcomes. In addition to directly affecting maternal-child interactions, reducing maternal depression may have indirect effects on child well-being through facilitating actions that change parental occupation or reduce family stress (Golden, Loprest, \& Mills, 2012; National Research Council \& Institute of Medicine, 2009; Rost, Smith, \& Dickinson, 2004; Schoenbaum et al., 2002).

Given the research findings on parental and children's mental health outcomes, the authors posit that CSAs may be similarly associated with children's physical health. SEED OK findings suggest, even though CSAs cannot change the underlying conditions that challenge children's mental or physical health, they may interrupt the processes in which poverty and family instability influences children's health (e.g., Council on Community Pediatrics, 2016; McKay et 
al., 2014; Morris et al., 2017). However, no research exists examining the association between CSAs and children's health. This study is a first attempt at addressing this knowledge gap. Further, this study examines whether the effects of CSAs are stronger for opt-in CSA designs or opt-out CSA designs. In opt-in designs, families must sign up to participate in the program. In contrast, in opt-out programs, families are automatically enrolled into the program and must disenroll from the program if they decide not to participate. Maine's Harold Alfond College Challenge is the only CSA program that shifted its enrollment policy from opt-in to opt-out, allowing researchers to examine the effects of opt-in and opt-out designs. The following offers an overview of this program.

HACC is an important CSA to study for being the only known CSA program to shift from opt-in to opt-out as well as the oldest statewide CSA program. Given that the growing number of states modeling their CSA programs after, research is much needed to examine the long-term effects of CSAs on educational, employment, and economic outcomes as well as the short-term effects on interim outcomes, such as reading and math achievement, health, and educational expectations. The current study aims to address a knowledge gap regarding the relationship between CSAs and children's health outcomes using data from the oldest statewide CSA program in the US. Specifically, this study examines the following hypothesis:

1) Do children with an Alfrond Grant have better parent-rated health than those who do not have an Alfrond Grant?

2) Do children who received an Alfond Grant during the opt-in period have better parent-rated health than those who received an Alfond Grant during the opt-out period?

3) Do children who received an Alfond Grant during the opt-in period have better parent-rated health than those who do not have an Alfond Grant?

4) Do children who received an Alfond Grant during the opt-out period have better parent-rated health than those who do not have an Alfond Grant?

Moreover, research that indicates that opt-in families are more likely to be high-income and more educated raises several additional considerations (e.g., Huang, Beverly, Clancy, Lassar \& Sherraden, 2013). First, we hypothesize that opt-out programs are likely to produce worse outcomes on average for children than opt-in programs. This aligns with critiques often heard in the field of studies using data from families who sign-up to be in a CSA program or who open a bank account on their own to save for college. More specifically, the critique is, positive results using an opt-in sample are susceptible to selection bias because families who sign-up are fundamentally different (e.g., higher-income and more educated) from families who do not sign-up. Therefore, we suggest, that if there is no statistical difference between the opt-in group and the opt-out group in this study, this strengthens our confidence that differences between opt-in or opt-out and the comparison regarding children's health are more likely to be due to having a CSA and not some other factor. 
Regarding opt-in and opt-out participants and children's health, we hypothesize that the difference between opt-in and the comparison group will be stronger than it is for opt-out. We suggest this is because of the larger percentage of higher-income more educated children in the opt-in group compared to the opt-out group. This is based on a well-established body of research that suggests children from higher-income and higher educated households are more likely to have better health outcomes than their counterparts living in lower-income and less educated families (Hanson \& Chen, 2007). Given that opt-out programs, which priorities inclusion, have more children from low-income and less educated families, we posit that the relationship between CSAs and children's health outcomes will be weaker than in opt-in programs.

\section{Methods}

A random sample of qualifying parents (i.e., parents who had a child born during the targeted dates and during the screening process) were chosen by Pan Atlantic Research, a Maine-based market research and consulting firm specializing in public policy issues. Random sampling refers to the method used to select households from the population to participate in this study. This was done to help ensure representativeness of the sample. However, it is important to point out that random sampling is different from random assignment. In a random assignment, all households in the population would have had an equal probability of being selected to participate in this study; this is not the case here. Given this, this study does not proport to test for causal relationships, instead, this study tests for whether correlational relationships.

Data collection was conducted using a 63 -item survey that was developed by several researchers. Questions included in the survey qualifying criteria, educational expectation, health and education history of the child, household finance, college saving and child's saving account, college cost, family relationship, as well as socio-demographic information. For sampling purposes, Pan Atlantic purchased a total number of 8000 phone records of parents with children born between 2008 and 2017 (i.e. the sample pool), participants were selected if they were a Maine resident and at least one child was born between 2008 and 2017. Data collection began in September of 2018 and ended in March of 2019, through online surveys $(n=170)$ and phone interviews $(n=600)$. More specifically, there were 300 phone surveys conducted between September 18, 2018 and October 12, 2018; 170 online surveys between September 26, 2018 and October 6, 2018; and 300 additional phone surveys between March 4, 2019 and March 18, 2019.

Phone surveys were conducted by Pan Atlantic with qualifying parents using a list purchased from CAS Inc. CAS Inc. database includes 100,000,000 US households. Phone lists comprised exclusively cell phone numbers due to the fairly young age range of the targeted parents. For the online surveys, Pan Atlantic Research used a panel of Maine parents purchased from Dynata's database, a 
nationally recognized research panel company with a reach of over $30,000,000$ US households. The online version of the survey was hosted on the platform Survey Gizmo. Both vendors were given the following parameters for survey participants: 1) Maine resident and 2) At least one child born between 2008 and 2017, inclusive. Additionally, respondents were screened at the beginning of the survey to ensure that they fell within the target universe. This reported included a final analytical sample of $n=744$ participants.

\section{Measures:}

Dependent variable. Parent-rated children's health was measured by a single-item question "In general, this child's health is ...?" Parents responded to a Likert scale ranging from " $1=$ Excellent" to " $5=$ Poor". The final score was recoded (ranging from 1 to 5 ) so that higher score represents better parent-rated children's health. Given the nature of this variable, we followed previous studies and dichotomized the variable into " $1=$ Excellent or very good health" versus " $0=$ Good, fair or poor"

Creation of Variables of Interest. Two questions and administrative data were used to determine a child's Alfond Grant receipt status. The two questions are 1) "In which year and month was this child born" and 2) "Does he/she [your child] have an Alfond Grant? ( 1 = Yes, $2=$ No)". The receipt status variable was created with the following categories: " $0=$ did not apply for an Alfond Grant during the opt-in period", " 1 = applied and received an Alfond Grantprior during opt-in period", " 2 = automatically received an Alfond Grant after 2013 and knew his/her child had a grant", and " 3 = automatically received an Alfond Grant after 2013 but did not know his/her child had a grant". The Alfond Grant receipt status variable is used to create three other variables described below and used in the analysis.

Combined Alfond Grant. The combined Alfond Grant variable is a bivariate variable that collapses families who signed up for Alfond Grant during the opt-in period and families who automatically received an Alfond Grant whether they knew it or not during the opt-out period. The comparison group are families who during the opt-in period did not sign up to receive the Alfond Grant. The receipt status variable was recoded as, " $1=$ participant received an Alfond Grant in either the opt-in or opt-out period" versus " $0=$ participant did not receive Alfond Grant". Odds ratios are presented for combined Alfond Grant vs comparison. This variable was created to test whether having an Alfond Grant is associated with parent rated children's health.

Alfond Grant Policy. The Alfond Grant policy variable is a three-level variable. The receipt status variable was recoded as, " $2=$ participant received an Alfond Grant during the opt-in period opt-in", "1 = participant received an Alfond Grant during the opt-out period opt-out", versus " $0=$ participant did not receive Alfond Grant-comparison". Odds ratios are presented for opt-in vs comparison, opt-out vs comparison, and opt-in vs opt-out. The Alfond Grant Policy variable tests whether findings are different depending on whether families were enrolled during the opt-in period or the opt-out period. 
Covariates. To investigate the association between Alfond Grant receipt and parent-rated children's health, this study also controlled for important covariates. Demographic covariates included: a child's age (in years), gender ( $1=$ male, $2=$ female $)$ and race $(1=$ Caucasian, $2=$ non-White $)$. Other important covariates were: 1) family income, 2) parent's education, 3) parent's relationship to the child, and 4) the child's diagnosed health condition.

Family income was measured by asking the parents "Which of the following ranges best represents your total household income from all sources before taxes and other deductions in calendar year 2017? Please include all income such as income from work, investments and alimony." Parents responded by reporting from " $1=\$ 15,000$ or less", " $2=15,001-\$ 35,000 "$ to " $9=155,001-\$ 175,000$ ", " $10=$ More than $\$ 175,000$ ". Based on national poverty lines and previous studies (e.g., Amstadter et al., 2010; Nguyen et al., 2011), this variable was recoded into " 1 = low income" ( $\$ 35,000$ or lower), " $2=$ middle income" $(\$ 35,001-\$ 115,000)$, and " 3 = high income" ( $\$ 115,001$ or higher).

Parents' education was measured by asking "What is the highest level of education you have completed?" Parents responded by selecting from " $1=$ some high school" to " $9=$ Ph.D., M.D., Law degree, or other high-level professional degree". The variable was recoded into " $1=$ up to high school or equivalent", " $2=$ Occupational school or some college", " 3 = Bachelor's degree”, and " 4 = Graduate degree or higher".

Parents' relationship to the child was measured by asking "What is your relationship to this child?" Participants selected from " 1 = biological mother", " $2=$ biological father" to " $7=$ female guardian", " $8=$ male guardian". The variable was recoded into " 1 = biological mother", " 2 = biological father", and " $0=$ other types of primary caregiver".

The child's diagnosed physical health condition was measured by asking the parent "over the past 12 months, has a doctor or health professional ever diagnosed (or said) that this child has any of the following condition? [select all that apply]". The parent checked all applicable items from a list of 9 items such as asthma, anemia, diabetes, and seizures. A summed score with possible values from 0 to 9 , with a higher score indicates worse physical health condition. All descriptive statistics about measures are presented in Table 1.

\section{Data analysis:}

Data analyses were conducted using STATA version 15 SE (Stata Corp, 2017).

Descriptive statistics were conducted to summarize the sample characteristics. Logistic regression analyses were conducted to evaluate parent-rated children's health as a function of CSA enrollment while controlling for important covariates. For categorical CSA enrollment variables, we first dichotomized the CSA enrollment variable into opt-in/opt-out versus comparison to determine if there exists a difference among those who received CSA versus those who did not. In addition, we included each of the three forms of CSA enrollment variable in a logistic regression model separately to assess the relationship. We switched the 
reference group to obtain odds ratio coefficients for different subgroup comparisons, for example, opt-in versus comparison (reference), opt-out versus comparison (reference), and opt-in versus opt-out (reference). Moreover, given there was a shift in 2014 HACC from an opt-in program to an opt-out program, all children born in 2013 whose parents had not already opted into HACC were retroactively signed up for HACC in 2014. As a result, we conducted sensitivity analysis by excluding 67 children who were born in 2013. Our findings remain the same therefore only the full sample results (including all children) presented here ${ }^{2}$.

Table 1. Descriptive statistics of study participants and variables $(\mathrm{N}=744)$.

\begin{tabular}{|c|c|c|c|c|c|c|c|c|c|}
\hline \multirow[t]{3}{*}{ Variable $^{1}$} & \multicolumn{2}{|c|}{ Combined Alfond Grant ${ }^{2}$} & \multicolumn{2}{|c|}{ Opt-In Alfond Grant } & \multicolumn{2}{|c|}{ Opt-Out Alfond Grant } & \multicolumn{2}{|c|}{ Comparison } & \multirow[t]{2}{*}{ Difference $^{3}$} \\
\hline & \multicolumn{2}{|c|}{$(\mathrm{N}=744)$} & \multicolumn{2}{|c|}{$(\mathrm{n}=343)$} & \multicolumn{2}{|c|}{$(\mathrm{n}=203)$} & \multicolumn{2}{|c|}{$(\mathrm{n}=198)$} & \\
\hline & Mean/SD & Freq. (\%) & Mean/SD & Freq. (\%) & Mean/SD & Freq. (\%) & Mean/SD & Freq. (\%) & \\
\hline Age & $8.20 / 2.73$ & & $9.77 / 1.26$ & & $4.47 / 1.36$ & & $9.68 / 1.31$ & & $<.001$ \\
\hline Female child & & $452(59)$ & & $202(59)$ & & $114(56)$ & & $126(64)$ & $=.302$ \\
\hline Race (\% White) & & $728(95)$ & & $328(96)$ & & $191(94)$ & & $185(93)$ & $=.511$ \\
\hline \multicolumn{10}{|l|}{ Income } \\
\hline$\leq 35,000$ & & $134(18)$ & & $45(13)$ & & $40(20)$ & & $43(22)$ & $=.074$ \\
\hline $35,001-115,000$ & & $531(70)$ & & $248(73)$ & & $136(68)$ & & $132(68)$ & \\
\hline$\geq 115,000$ & & $96(12)$ & & $47(14)$ & & $25(12)$ & & $20(10)$ & \\
\hline \multicolumn{10}{|l|}{ Education } \\
\hline HS or equivalent & & $197(28)$ & & $90(27)$ & & $58(32)$ & & $42(25)$ & $=.475$ \\
\hline Some college & & $73(10)$ & & $29(9)$ & & $24(13)$ & & $16(9)$ & \\
\hline Bachelor's degree & & $293(42)$ & & $139(42)$ & & $70(38)$ & & $74(45)$ & \\
\hline$\geq$ Graduate degree & & $137(20)$ & & $70(22)$ & & $31(17)$ & & $33(20)$ & \\
\hline \multicolumn{10}{|l|}{ Relationship to child } \\
\hline Other PC & & $27(3)$ & & $11(3)$ & & $10(5)$ & & $4(3)$ & $<.001$ \\
\hline Biological mother & & $428(56)$ & & $163(48)$ & & $126(62)$ & & $124(62)$ & \\
\hline Biological father & & $315(41)$ & & $169(49)$ & & $67(33)$ & & $70(35)$ & \\
\hline Child's health diagnosis & $.34 / .61$ & & $.37 / .36$ & & $.22 / .48$ & & $.39 / .60$ & & $=.319$ \\
\hline \multicolumn{10}{|l|}{ Parent rated child health } \\
\hline Poor or fair or good & & $68(9)$ & & $25(7)$ & & $23(11)$ & & $16(8)$ & $=.254$ \\
\hline Very good or excellent & & $702(91)$ & & $318(93)$ & & $180(89)$ & & $182(92)$ & \\
\hline
\end{tabular}

1. HS or equivalent $=$ high school degree or equivalent. Other PC $=$ other primary caregiver. 2 . Freq. $=$ frequency. 3 . Between group difference was tested using ANOVA for continuous variables and Chi-square test for categorical variables across all three groups. All percentages rounded to the nearest who number.

${ }^{2} \mathrm{We}$ choose not to run propensity score analysis because of the limited number of controls available. This would limit the viability of such a model. Additionally, for this study, we adopted a $\mathrm{p}$ value of .10 for statistical significance given the relatively small sample size and the pilot nature of this study. 


\section{Results}

Table 1 presents descriptive statistics of study participants $(\mathrm{N}=744)$. The average age of children in the opt-in group is about 10 years old, while it is about 4 to 5 years old for opt-out children. Further, in this sample of HACC children, a larger percentage of opt in children were female (59\%) than children whose families opted out (56\%) to HACC. Children born during the opt-out period are more likely (20\% vs $13 \%$ ) to live in families with annual incomes of $\$ 35,000$ or less and are less likely to have completed a college degree (17\% vs $22 \%)$ than children living in families who signed up for an Alfond Grant during the opt-in policy period. Parents reported data are more likely to be a child's biological father in the opt-in group (49\%) than those in the opt-out group (33\%). Parents from those who did not receive Alfond Grant reported comparable (no statistical difference) percentage of "excellent or very good" health than those received Alfond Grant (both in the opt-in and opt-out group).

Table 2 presents two models assessing the association between the Alfond Grant Policy variable and parent-rated children's health. Controlling for all covariates, in Model 1, parent-rated children's health was significantly different from families receiving CASA during either the opt-in or opt-out period than their counterparts who did not receive CSA (OR $=1.71,95 \%$ CI $(.94,3.08)$, $\mathrm{p}=.07)$. Parents from families that received an Alfond Grant were 1.71 times more likely to report "excellent or very good" health of their children than those who did not receive an Alfond Grant. Model 2 further evaluated if parent-rated children's health was significantly different across three CSA groups: 1) receipt CSA during opt-in period, 2) receipt CSA during opt-out period, and 3) did not receive CSA (comparison). Families received Alfond Grant during the opt-in period were 1.86 times more likely to report "excellent or very good" health of their children than those who did not receive Alfond Grant (comparison) during the opt-in period ( $\mathrm{OR}=1.86,95 \% \mathrm{CI}(1.01,3.45), \mathrm{p}=.048)$. The differences between opt-out group versus comparison and between opt-in versus option-out group were not statistically significant. In summary, using data from the Maine's Harold Alfond College Challenge program, we were able to establish a significant association between receiving CSA and parent reported child's health, suggesting the impact of CSA on children's health wellness.

\section{Discussion}

Based on previous research on the relationship between Children's Savings Accounts (CSAs) and parental and children's mental health outcomes (e.g., Huang, Sherraden, Kim, \& Clancy, 2014), the authors posited that CSAs may be similarly associated with children's physical health status measured by parent-rated children's health. However, to date, no research specifically tests the relationship between CSAs and children's physical health status. Using data from the Harold Alfond College Challenge (HACC), one of the oldest and most well-known CSA programs in the United States, this study found a correlation between HACC's CSA program and children's physical health status. 
Table 2. Parent reported children's health as a function of Alfond Grant Policy $(n=669)^{1}$.

\begin{tabular}{|c|c|c|c|c|}
\hline & \multicolumn{2}{|c|}{ Model 1} & \multicolumn{2}{|c|}{ Model 2} \\
\hline & OR & {$[95 \% \mathrm{CI}]$} & OR & {$[95 \% \mathrm{CI}]$} \\
\hline Constant & 4.53 & {$[.56,36.86]$} & 12.37 & {$[.75,203.44]$} \\
\hline \multicolumn{5}{|l|}{ Alfond Grant Policy ${ }^{2}$} \\
\hline Opt-in vs Comparison & & & $1.86^{\star *}$ & {$[1.01,3.45]$} \\
\hline Opt-out vs Comparison & & & .92 & {$[.25,3.28]$} \\
\hline$(\text { Opt-in vs Opt-out })^{3}$ & & & 2.06 & {$[.56,7.59]$} \\
\hline \multicolumn{5}{|l|}{ Combined Alfond Grant } \\
\hline Opt-in/Opt-out vs Comparison & $1.71^{*}$ & {$[.94,3.08]$} & & \\
\hline Age & 1.02 & {$[.91,1.41]$} & .92 & {$[.74,1.14]$} \\
\hline Male child (ref: female) & $1.79^{*}$ & {$[.99,3.22]$} & $1.79^{*}$ & {$[.99,3.22]$} \\
\hline Caucasian child (ref: non-White) & .77 & {$[.24,2.42]$} & .74 & {$[.23,2.35]$} \\
\hline \multicolumn{5}{|l|}{ Income (ref: low) } \\
\hline Middle income & .80 & {$[.37,1.72]$} & .80 & {$[.37,1.71]$} \\
\hline High income & 1.43 & {$[.45,4.52]$} & 1.41 & {$[.45,4.45]$} \\
\hline \multicolumn{5}{|l|}{ Education (ref: HS or equivalent) } \\
\hline Some college & 1.41 & {$[.54,3.67]$} & 1.44 & {$[.55,3.77]$} \\
\hline Bachelor's degree & 1.22 & {$[.66,2.26]$} & 1.25 & {$[.68,2.32]$} \\
\hline$\geq$ Graduate degree & 2.01 & {$[.86,4.70]$} & 2.03 & {$[.87,4.75]$} \\
\hline \multicolumn{5}{|l|}{ Relationship to child (ref. other) } \\
\hline Biological mother & .92 & {$[.19,4.52]$} & .90 & {$[.18,4.45]$} \\
\hline Biological father & 1.09 & {$[.21,5.56]$} & 1.04 & {$[.20,5.37]$} \\
\hline \multicolumn{5}{|l|}{ Child's health diagnosis } \\
\hline 1 medical diagnosis & .83 & {$[.45,1.53]$} & .84 & {$[.45,1.56]$} \\
\hline$>1$ medical diagnosis & .54 & {$[.15,2.03]$} & .55 & {$[.15,2.06]$} \\
\hline
\end{tabular}

${ }^{* *} p<.05,{ }^{*} p<.10 .1 . \mathrm{OR}=$ Odds Ratio. $95 \% \mathrm{CI}=95 \%$ Confidence Interval. 2. Alfond Grant Policy is a three-level variable which contains " $2=$ participant received an Alfond grant during the opt-in period (opt-in)", " 1 = participant received an Alfond grant during the opt-out period (opt-out)", versus " $0=$ participant did not receive Alfond grant (comparison)". 3. Coefficient for variables in parenthesis are obtained using the same model but with different reference group.

To test this relationship, the authors created two different variables. The first variable is the combined Alfond Grant variable. It combines families who signed up for Alfond Grant during the opt-in period and families who were automatically received an Alfond Grant whether they knew it or not during the opt-out period. In opt-in designs, families must sign up to participate in the program. In contrast, in opt-out programs, families are automatically enrolled into the program and must disenroll from the program to not participate. Findings indicate that receiving an Alfond Grant is significantly associated with better parent-rated children's health. This is in alignment with previous findings on CSAs and parental and children's mental health outcomes (e.g., Huang, Sherraden, 
Kim, \& Clancy, 2014; Huang, Sherraden, \& Purnell, 2014). However, a question arises whether the opt-in cohort or opt-out cohort is driving the findings.

Researchers studying CSAs have suggested that the only way to truly achieve inclusivity is to adopt an opt-out design (Clancy \& Beverly, 2017). The SEED OK CSA experiment provided the strongest evidence that supporting automatic enrollment is the most effective way to assure every kid gets an account. Parents in the treatment group are automatically enrolled in the state 529 plan and granted a $\$ 1000$ initial deposit, unless they take the explicit step of opting out. In SEED OK, only one household opted out, resulting in $99.9 \%$ account ownership (Clancy et al., 2016). While automatic enrollment may guarantee all children get an account, research has shown that children from families who opt-in may be different than children from families who are automatically put into a CSA program. For example, Huang and colleagues (Huang et al., 2013) found that families participating in Maine's HACC during the opt-in period were more likely to be financially-sophisticated even for families with high income, high education, and other attributes that may make them more likely to have better outcomes (e.g., better health outcomes).

To address the question of whether opt-in and opt-out cohorts have different outcomes regarding parents rated children's health, a three-level Alfond Grant variable was created with the following categories: 1) opt-in, 2) opt-out, and 3) comparison. When comparing opt-in children's physical health to opt-out children's physical health, we find no statistical difference. That is, opt-in children in this study are not statistically different from opt-out children regarding parent rated children's health. While this finding cannot fully rule out the possibility of another factor explain improvement in health outcomes among children in HACC, this finding does strengthen our confidence that differences are due to owning a CSA and not some other factor.

We also posited that the difference between opt-in and the comparison group would be stronger than it is for opt-out and the comparison group given the difference between the larger percentage of higher-income more educated children in the opt-in group compared to the opt-out group. There also seems to be some evidence for this. We did find statistical difference in health outcomes of children between the opt-in and comparison group and the opt-out group and the comparison group. However, it is important to not in the case of the opt-in group and the comparison group the difference was marginally significant ( $\mathrm{p}$ $<.07)$. Age differences between opt-in and opt-out might explain why there is a stronger statistical difference in the case of the opt-in group (versus comparison) and not the opt-out group. Given the design of the program, children in the opt-out group were on average 5 years younger than children in the opt-in group. It might be, as children in the opt-out program become older, differences may be more detectible. Alternatively, it might be because there is a higher percentage of low-income and less educated children in the opt-out group and previous research indicates that children from these conditions are more likely to 
report worse health outcomes than children living in families in high-income and more educated households (Hanson \& Chen, 2007).

\section{Conclusion}

Building on a compelling body of literature regarding the positive effects of owning a Child Saving's Account (CSA) on a variety of children's developmental and mental health outcomes, this study extended this line of inquiry by examining the association between CSA ownership and children's physical health status. A couple of limitations are worth noting. First, findings from this study are specific to HACC, therefore not be generalizable to other CSA programs; Second, given the nature of the study, we had a small sample size and low statistical power. Third, given the distribution of the outcome data and the small sample size, we dichotomized the outcome variable. With a larger sample size in the future, we would be able to conduct more nuanced analysis ("poor or fair" versus "good" versus "excellent or very good"). Finally, our population is relatively young. Longitudinal studies are needed to follow the impact of CSA programs on the health trajectories of participants.

Notwithstanding the limitations mentioned above, this is the first study to examine this relationship. Findings provide evidence of a statistically significant positive association; however, more research is needed before policy conclusions can be drawn. Moreover, this study finds evidence that these positive effects were possibly driven by perceived account ownership. That is, it might be important that people know they have an account for effects to be observed. This is also an area that needs further exploration.

\section{IRB Statement}

This is a secondary data analysis thus IRB review is not applicable.

\section{Funding and Acknowledgements}

This report could not have been done without the generous support of the Charles Stewart Mott Foundation.

\section{Conflicts of Interest}

The authors declare no conflicts of interest regarding the publication of this paper.

\section{References}

Adler, N. E., Glymour, M. M., \& Fielding, J. (2016). Addressing Social Determinants of Health and Health Inequalities. The Journal of the American Medical Association, 316, 1641-1642. https://doi.org/10.1001/jama.2016.14058

Amstadter, A. B., Begle, A. M., Cisler, J. M., Hernandez, M. A., Muzzy, W., \& Acierno, R. (2010). Prevalence and Correlates of Poor Self-Rated Health in the United States: The National Elder Mistreatment Study. The American Journal of Geriatric Psychiatry, 18, 615-623. https://doi.org/10.1097/JGP.0b013e3181ca7ef2 
Azzonlini, D., Martini, A., Rettore, E., Romano, B., Schizzerotto, A., \& Vergolini, L. (2018). Testing a Social Innovation in Financial Aid for Low-Income Students: Experimental Evidence from Italy. IZA Institute of Labor Economics. https://ftp://repec.iza.org/RePEc/Discussionpaper/dp11625.pdf

Carstensen, L. (2011). A Long Bright Future: Happiness, Health, and Financial Security in an Age of Increased Longevity. New York: Public Affairs.

Clancy, M. M., \& Beverly, S. G. (2017). Statewide Child Development Account Policies: Key Design Elements. (CSD Policy Report 17-30). St. Louis, MO: Washington University, Center for Social Development.

Council on Community Pediatrics (2016). Poverty and Child Health in the United States. Pediatrics, 137, e20160339. https://doi.org/10.1542/peds.2016-0339

de Andrade, L. O. M., Pellegrini Filho, A., Solar, O., Rígoli, F., de Salazar, L. M., Serrate, P. C. F., Atun, R. et al. (2015). Social Determinants of Health, Universal Health Coverage, and Sustainable Development: Case Studies from Latin American Countries. The Lancet, 385, 1343-1351. https://doi.org/10.1016/S0140-6736(14)61494-X

Diez Roux, A. V. (2012). Conceptual Approaches to the Study of Health Disparities. Annual Review of Public Health, 33, 41-58.

https://doi.org/10.1146/annurev-publhealth-031811-124534

Elliott, W. (2009). Children's College Aspirations and Expectations: The Potential Role of College Development Accounts (CDAs). Children and Youth Services Review, 31, 274-283. https://doi.org/10.1016/j.childyouth.2008.07.020

Elliott, W. (2013). Small-Dollar Children's Savings Accounts and Children's College Outcomes. Children and Youth Services Review, 35, 572-585. https://doi.org/10.1016/j.childyouth.2012.12.015

Elliott, W., \& Lewis, M. (2018). Making Education Work for the Poor: The Potential of Children's Savings Accounts. New York: Oxford University Press.

Elliott, W., Kite, B., O’Brien, M., Lewis, M., \& Palmer, A. (2018). Initial Elementary Education Finding from Promise Indiana's Children's Savings Account Program. Children and Youth Services Review, 85, 295-306. https://doi.org/10.1016/j.childyouth.2018.01.004

Golden, O., Loprest, P., \& Mills, G. (2012). Economic Security for Extremely Vulnerable Families: Themes and Options for Workforce Development and Asset Strategies. Washington DC: The Urban Institute.

http://www.urban.org/research/publication/economic-security-extremely-vulnerable-f amilies-themes-and-options-workforce-development-and-asset-strategies

Hanson, M. D., \& Chen, E. (2007). Socioeconomic Status and Health Behaviors in Adolescence: A Review of the Literature. Journal of Behavioral Medicine, 30, 263. https://doi.org/10.1007/s10865-007-9098-3

Huang, J., Beverly, S., Clancy, M., Lassar, T., \& Sherraden, M. (2013). Early Program Enrollment in a Statewide Child Development Account Program. Journal of Policy Practice, 12, 62-81. https://doi.org/10.1080/15588742.2012.739124

Huang, J., Kim, Y., \& Sherraden, M. (2016). Material Hardship and Children's SocialEmotional Development: Testing Mitigating Effects of Child Development Accounts in a Randomized Experiment. Child: Care, Health and Development, 43, 89-96. https://doi.org/10.1111/cch.12385

Huang, J., Sherraden, M., \& Purnell, J. Q. (2014). Impacts of Child Development Accounts on Maternal Depressive Symptoms: Evidence from a Randomized Statewide Policy Experiment. Social Science \& Medicine, 112, 30-38.

https://doi.org/10.1016/j.socscimed.2014.04.023 
Huang, J., Sherraden, M., Kim, Y., \& Clancy, M. (2014). Effects of Child Development Accounts on Early Social-Emotional Development an Experimental Test. Journal of American Medical Association Pediatrics, 168, 265-271. https://doi.org/10.1001/jamapediatrics.2013.4643

Kim, Y., Sherraden, M., Huang, J., \& Clancy, M. (2015). Child Development Accounts and Parental Educational Expectations for Young Children: Early Evidence from a Statewide Social Experiment. Social Service Review, 89, 99-137.

https://doi.org/10.1086/680014

Lewis, M., \& Elliott, W. (2015). A Regional Approach to Children's Savings Account Development: The Case of New England. Lawrence, KS: Center on Assets, Education, and Inclusion (AEDI).

McKay, M. M., Alicea, S., Elwyn, L., McClain, Z. R., Parker, G., Small, L. A., \& Mellins, C. A. (2014). The Development and Implementation of Theory-Driven Programs Capable of Addressing Poverty-Impacted Children's Health, Mental Health, and Prevention Needs: CHAMP and CHAMP+, Evidence-Informed, Family-Based Interventions to Address HIV Risk and Care. Journal of Clinical Child \& Adolescent Psychology, 43, 428-441. https://doi.org/10.1080/15374416.2014.893519

Morris, A. S., Robinson, L. R., Hays-Grudo, J., Claussen, A. H., Hartwig, S. A., \& Treat, A. E. (2017). Targeting Parenting in Early Childhood: A Public Health Approach to Improve Outcomes for Children Living in Poverty. Child Development, 88, 388-397. https://doi.org/10.1111/cdev.12743

National Research Council and Institute of Medicine (NRC/IOM) (2009). Depression in Parents, Parenting, and Children: Opportunities to Improve Identification, Treatment, and Prevention.

Nguyen, P. L., Gu, X., Lipsitz, S. R., Choueiri, T. K., Choi, W. W., Lei, Y., Hu, J. C. et al. (2011). Cost Implications of the Rapid Adoption of Newer Technologies for Treating Prostate Cancer. Journal of Clinical Oncology, 29, 1517. https://doi.org/10.1200/JCO.2010.31.1217

Powell, G. (2014). Remarks to the Portland Regional Chamber of Commerce and Announcement of "Automatic Enrollment" for the Harold Alfond College Challenge. http://www.haroldalfondfoundation.org/pdf/announcements/EggsIssues3.4.14FINAL 000.pdf

Prosperity Now (2018). The Movement Takes off: The State of the Children's Savings Field 2017. Washington, DC.

https://prosperitynow.org/resources/movement-takes-state-childrens-savings-field-201 7

Rost, K., Smith, J., \& Dickinson, M. (2004). The Effect of Improving Primary Care Depression Management on Employee Absenteeism and Productivity. A Randomized Trial. Medical Care, 42, 1202-1210. https://doi.org/10.1097/00005650-200412000-00007

Schoenbaum, M., Unutzer, J., McCaffey, D., Duan, N., Sherbourne, C., \& Wells, K. (2002). The Effects of Primary Care Depression Treatment on Patients' Clinical Status and Employment. Health Services Research, 37, 1145-1158.

https://doi.org/10.1111/1475-6773.01086

Sherraden, M. (1991). Assets and the Poor: A New American Welfare Policy. Armonk, NY: M.E. Sharpe, Inc.

Stata Corp (2017) Stata Statistical Software: Release 15. College Station, TX: StataCorp LLC. 